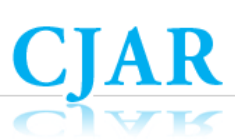

Canadian Journal of Action Research

Volume 19, Issue 3, 2018, pages 5-33

\title{
MAPPING COMPLEXITY IN AN ELEMENTARY MATHEMATICS CLASSROOM
}

\author{
Evan Throop Robinson \\ St. Francis Xavier University
}

\begin{abstract}
To develop the mathematical discourse of an elementary classroom, I designed an action research project around an intervention of Open Space Technology (OST). Guided by the theoretical perspective of complexity thinking, OST principles created a 'space' or a new structure for learning, where participants self-organized according to interests and needs around a common purpose. I focused this article on the design of a mapping methodology I created for OST to provide teacher-researchers with a tool that may lead, in conjunction with a framework for discourse analysis, to a better understanding of how student movement and interactions promote productive math talk.
\end{abstract}

KEYwords: Open Space Technology; Mathematics; Complexity Thinking

To engage with our students as persons is to affirm our own completeness, our consciousness of spaces still to be explored, desires still to be tapped, possibilities still to be opened and pursued. ... We have to find out how to open such spheres, such spaces, where a better state of things can be imagined ... I would like to think that this can happen in classrooms, in corridors, in schoolyards, in the streets around.

(Greene, 1986, p. 429) 


\section{INTRODUCTION}

Developing classroom discourse is arguably one of the greatest challenges facing teachers in the elementary mathematics classroom. Current guiding principles and instructional practices from the National Council of Teachers of Mathematics focus teachers on using effective teaching practices to engage students in meaningful learning. In the document Principles to Actions: Ensuring mathematical success for all (NCTM, 2014), the facilitation of meaningful mathematical discourse is one of the eight high-level practices of effective teaching "in order to build shared understanding of mathematical ideas by analyzing and comparing student approaches and arguments" (p. 10). With the proven value of discourse in mind, as a classroom teacher, I was continually faced with the challenges of augmenting the level of discourse in my classroom to create an inclusive space where students' voices could be heard. I turned to research-based material that would help me meet these standards successfully.

From a theoretical perspective, I reconsidered Pimm's influential research (1987) into how students speak mathematically. Pimm's work examined how students communicate in the mathematics classroom using both everyday language and a 'mathematical register' with respect to vocabulary, symbols or pictures. Kotsopoulos reiterated this, by arguing that hearing mathematics discourse is often "like hearing a foreign language"; thus, challenging teacher-researchers to support students in learning a new language and "to consider thoughtfully the discourse that occurs in our classroom and in what contexts students experience the discourse" (2007, p. 304).

From a practical standpoint, I found many instructional strategies and practices that promote the value of 'Math Talk' in developing the classroom discourse. Chapin, O'Connor and Canavan-Anderson's (2003) compilation of classroom data, to support students' discussions in mathematics, described significant purposes and uses of mathematical talk in the classroom. These include: developing conceptual understanding, computational procedures, solution strategies and reasoning. They provided a useful framework for classroom discussions, often echoed by other researchers. This framework focuses on how teachers can organize instruction so as to modify the structure of students' participation to promote productive math talk (Cobb, Wood \& Yackel, 1993; Kamii, 2000; Lampert, 1990). A strong tradition of research in classroom discourse continues to grow. Some of the most notable include: teacher's re-voicing (Forman \& Ansell, 2001); student's restating (Chapman, 2009; Moschkovich, 2007); prompting (Manouchehri \& St. John, 2006); grouping considerations (Dekker, Elshout-Mohr, \& Wood, 2006; Sherin, 2002); and establishing ground rules for respectful talk and equitable participation (Garrett, 2008; Henning, 2005; Wachira, Pourdavood \& Skitzki, 2013). In part, these researchers addressed issues of concern to me; for example, valuing the importance of fostering rich mathematics discourse. At the same time, I also recognized that, in the classroom, myself and my peers were doing too much talking most of the time. The discourse in my classroom became over reliant on the teacher and privileged teacher-directed discourse over more studentcentered discourse. A clear research focus presented itself to me. How could students become more participatory and responsible for the discourse of mathematics to make it more meaningful and authentic? 
Brooks and Dixon (2013) promoted student-led discourse by changing the traditional classroom requirement of raising your hand to speak in a Grade 2 classroom. In their discourse analysis, they underscored the benefits of opening a space for conversations in mathematics. They described the transformation of classroom discourse from predominantly teacher-directed to student-driven, "by allowing our elementary school students to speak directly to one another, something that was clearly powerful for these students" (p. 88). This work deeply resonated with me, as I recognized how a simple change could significantly impact discourse.

Inspired by the power of this simple change (do not raise hands), I sought other methodologies that were equally 'simple' to further foster mathematical discourse through direct, meaningful student exchanges. I subsequently discovered a powerful way to change classroom discourse through a meeting methodology used largely in adult learning and meeting environments, known as Open Space Technology (OST) (Owen, 1997a). OST, which I will explain further below, evolved as Harrison Owen worked with groups encouraging self-organization around common issues. He described OST first as a means to increase the potential for meaningful communication; and second, as a way to build on existing networks within an organization (1997b). He also described OST as complexity thinking in action (2000) as it meets the requirements of complex systems where networks of individuals collaborate to create a new learning system. The power of this methodology is that it can be used by anyone 'who has a good heart and a good mind' (1997a); therefore, any teacher, who so desires, could adopt OST and experiment with it to find out how it could open the classroom space for a variety of purposes. I saw the potential for OST, with the simplicity of its four principles, to provide a practical methodology for teachers to facilitate mathematical discourse among students to build shared understandings through meaningful and authentic exchanges.

Experimenting with such methodologies to discover their possibilities or limitations is critical for the teacher-researcher; however, as a novice researcher, I was met with the additional problem of seeing and hearing the concurrent conversations surrounding me so I could make sense of what on the surface, due to student movement between clusters of conversation, appeared chaotic. It occurred to me that, if I could map the sequence of students' movements to create a visual representation and also record all the conversations, I could then examine the discourse contextually; thereby enabling a fuller analysis of the students' exchanges. This article focuses on my search and creation of a method to make the intricate movements of a complex classroom visible for the purpose of tracking students' journeys (i.e., their learnings and contributions) in the multiple, concurrent conversations being held within a mathematics lesson, using OST as the methodology, which modifies the structure of students' participation to promote math talk.

Guiding my research, is the theoretical perspective of complexity thinking (Gleick, 1987; Waldrop, 1992) and its recognition of individuals and networks of individuals that contribute to the emergence of a learning system, exceeding individual efforts (Johnson, 2001; Sumara \& Carson, 1997). Complexity thinking asks researchers to pay attention to 
necessary conditions to generate emergence and to sustain a viable and adaptive learning system. These conditions include: internal diversity, redundancy, decentralized control, organized randomness, and neighbor interactions (Davis \& Simmt, 2003; Davis \& Sumara, 2005). Making the complex interactions visible, through mapping the sequence of student movements, helped determine if the minimum conditions of a complex learning system, particularly neighbor interactions, were met and; thereby, supportive of an emergent learning system.

Specifically, I focus this article on the mapping methodology I created for OST to provide teacher-researchers with a tool that may lead, in conjunction with a framework for discourse analysis, to a better understanding of how student movement and interactions promote productive talk. My primary question is: How might I make visible students' exchanges in an OST intervention to understand the take-up of student-centered mathematical discourse within the complex learning system of the elementary mathematics classroom?

\section{WHAT IS OST?}

Open Space Technology is a meeting methodology for large-group facilitation that promotes meaningful conversation, allows for new ways of thinking, and generates creativity and change (Daniel, 1994). Harrison Owen's observation of and experiences with meeting fatigue within the business culture led him to develop a particular methodology for richer discussion among office participants (1997a). Owen described the resulting synergy and excitement of using this technology in a corporate setting as fundamental "to enhance group functionality and creativity with direct ... results" (p. 147).

Clearly, actions based on observations of behavior in business settings cannot necessarily be un-problematically transferred into educational settings without a sound educational rationale. This is why it was necessary to conduct a thorough investigation of the broader theoretical field within which OST could be conceptualized in educational terms. In considering this educational rationale, I connected OST and its ideas of openness and selforganization as characteristics of complex systems and complexity thinking in education. Following this introduction to OST, I clarify these connections with complex learning systems to locate OST more clearly within an educational context.

OST principles create a 'space' or a new structure for learning, where participants selforganize according to interests and needs around a common purpose (Owen, 1997a). Participants come together in small circles to share experiences and passions, through which opportunities emerge for networking, visioning, and collaboration. In schools, OST may provide occasions for students to work together and to generate conversations around shared issues.

The principles are:

- Whoever comes is the right person - It is not necessary to have every person in the group join a conversation, just those people who care the most about that 
particular topic. If only one person comes, it might be a focused occasion for thinking and writing on the issue.

- Whatever happens is the only thing that could have - Participants let go of expectations and work with whatever unfolds.

- Whenever it starts is the right time - Creativity doesn't happen on a schedule. Everyone enjoys the flexibility of relaxed time constraints.

- When it's over, it's over - If a group finds a solution or reaches a conclusion in 20 minutes, people move on to the next group. If it takes 2 hours, people keep talking as others join in and/or leave independently (Corrigan, 2002b; Heft, 2005; Owen, 1997a).

One law, the Law of Mobility, reminds participants that if they are neither learning nor contributing to a group, they must leave and join a session in progress where they feel more useful and inspired (Corrigan, 2002b; Heft, 2005; Herman \& Corrigan, 2002; Owen, 1997a). The Law of Mobility sits at the heart of OST: participants have full freedom of choice and accountability for their own learning or contributions and can enter or leave a conversation when and if they choose. By choosing to enact the Law of Mobility, OST participants can take responsibility for their own learning. OST also reduces the likelihood of an individual or particular interest from exerting control or dominating a group, as people are always free to leave and find a place where their voice can be heard (O'Connor, 2005).

The OST design has three aspects:

(1) During the opening circle, individuals voluntarily create an agenda for discussion by posting a topic that is of concern to that individual. This includes a meeting time and a place to convene a conversation on that topic. There is no limit to the number of topics that may be posted; however, the facilitator asks that those posting topics be passionate enough about the topic to host the conversation.

(2) Participants sign up to work on issues of most interest. This supports the process of self-organization by all participants, as they are free to choose where they would most like to contribute and are also free to switch to another conversation at any time, given the Law of Mobility. Participants who choose not to join a conversation immediately become, in Owen's terms, Butterflies and Bumblebees. Owen describes Butterflies as "centers of non-action" (1997a, p. 100); yet, their mobility speaks to actions like moving through the space, listening in on conversations, and sharing energy with a group albeit non-verbally. These participants, much like the social butterfly may visit many groups, choosing to remain on the periphery of the conversations and to make occasional contributions. Bumblebees, on the other hand, like their namesakes in nature, are participants who move from one group to another, cross-pollinating ideas among them as they go (1997a). Significantly, all participants contribute in this complex system, either as they engage in one or multiple conversations or as they enact the Law of Mobility as Butterflies and Bumblebees. 
(3) The convener of the session hosts the conversations and records ideas so that they can be shared with everybody. These notes become the book of proceedings for the session and provide an account of the conversations.

Throughout the meeting phase, the facilitator 'holds space' for the participants to ensure the space is safe for openness and creativity (Owen, 1997a, p. 109). In a public setting, given full freedom of choice, participants may decide to leave the session or not attend in the first place. This would indicate that the initial invitation was not meaningful to the participant. In an educational setting, the obligation to attend school limits students' freedom; however, the option to invoke the Law of Mobility within the learning system acknowledges the responsibility of each student to participate and contribute in a way that is meaningful. This is a unique combination of theory and practice, as OST not only opens a collective space of possibilities for student engagement, classroom discourse and complexity in action, but provides teachers with a new model of inquiry for their own action research.

\section{RELEVANT LITERATURE: COMPLEXITY THINKING, OST AND EDUCATIONAL ACTION RESEARCH}

Action research is well suited to classroom research, with the aim of improving practice and understanding classroom dynamics more fully (Carr \& Kemmis, 1986; Kemmis \& McTaggart, 1988; McNiff \& Whitehead, 2010; Nichols \& Cormack, 2016). Foundational to this research was the opportunity to offer teachers a new methodology highlighting the complexity of a learning system's dynamics (Kincheloe \& Berry, 2004; Phelps \& Hase, 2002). My action research builds on the work of Complexivist Thinking (Capra, 1996; Doll, 1989) and, in an educational context, on the literature theorizing about complexity thinking using action research (Davis \& Simmt, 2003; Davis \& Sumara, 2006; Davis, Sumara \& LuceKapler, 2008; Stanley, 2009; Towers \& Davis, 2002). Corrigan (2002a) provided a clear theoretical discussion of OST and its applicability in children's education; yet, did not extend this to the practice level and offered no data from implementation. However, his insightful discussion spoke of students' empowerment in "holding the space" for their own learning to allow creativity and freedom to emerge. "Power," says Corrigan, "is not meted out like a ration, but rather is left for people to take as little or as much as they want.... This is true empowerment, because participants are invited to become empowered to the extent that they wish" (p. 2). By bringing together the theoretical perspective of complexity thinking with the design of the OST intervention, as complexity in action, I created a classroom space for such action and a means to generate rich data from the classroom discourse. Discourse theorists (Gee, 2011; Sfard, 2007) provided the foundation for my analytical framework; and, I adapted Truxaw and DeFranco's discourse model (2008) to create a classroom mapping tool that makes visible the student-led exchanges and shows the dynamics of a complex learning system.

My review of findings on interventions designed to improve mathematics classroom talk with the goal of enhancing students' learning, thinking and understanding of mathematics showed consistency among researchers aiming to raise achievement levels directly with students struggling with mathematics (Fuchs et al, 2008) or identified as having 
mathematics difficulties (Gersten, Jordan, \& Flojo, 2005). Interventions are most often seen as vital tools to help prevent or remediate such deficiencies in students (Janzen, 2005; Mong \& Mong, 2010). Effectiveness of interventions is primarily measured with pre- and post-tests designed to capture students' understanding at a particular moment to determine a cause and effect relationship. Complexity thinking compels the researcher to consider that the whole is greater than the sum of its parts and so calls for more holistic descriptions of the entire system and close analysis of the interrelationship of its parts. Dekker and Elshout-Mohr (2004), for example, analyzed interventions designed to stimulate interaction among students. They designed their research to distinguish "process-help intervention" (p. 43) from "product-help" (p. 44) interventions, both intended as tools to correct students' deficits. Their finding determined that process-help intervention was more effective in supporting students' mathematical thinking. The OST intervention builds on this process-help orientation, as it aims to enhance students' learning of mathematics by modifying how students might participate in mathematical talk.

\section{ACTION RESEARCH DESIGN}

Positionality, Participants and Research Phases

As a teacher, I come from the classroom and, through my teaching at university levels I have remained in the classroom. As an educator researching the practice of teachers, my research is rooted in the classroom yet I am uniquely positioned, as Greene (1993) has stated, as 'stranger' in a classroom that is not my own. Guided by Herr and Anderson's continuum of positionality (2005), I describe my own positionality as 'insider in collaboration with other insiders' (p. 31) with the benefit of entering this research space with new eyes and ears to see and hear students anew, as a stranger might for the first time, "look inquiringly and wonderingly on the world in which one lives (Greene, 1993, p. 93). In the introductory quote, Greene incites teachers' engagement with students to open spaces of possibilities and inspire them to imagine new opportunities. This provocation moved me to bring complexity thinking together with action research to explore possibilities for student participation in the discourse of mathematics. Action research was a suitable choice for the design because this research focuses on learning and change in classroom structure, organization and instructional methodology. The design opened a space for the necessary minimum conditions for emergence within a complex system and provided an opportunity for reflection on these changes through recursive cycles to further an understanding of students' take-up of mathematical discourse.

I conducted this research within a rural community school set in eastern Canada. There were 10 boys and 13 girls in the visibly homogeneous class. In the grade 6 classroom, six students received literacy support from a coach and two students met with the itinerant teacher for mathematics support. The teacher described the overall achievement of the class in mathematics as average to low and generally stronger in the areas of literacy and social studies.

In determining my action research design, I maintained a complexity thinking perspective for the research cycles, with a view to the participatory, cyclical and iterative process of 
action research (Carr \& Kemmis, 1986; Phelps \& Haas, 2002), wherein new knowledge arises out of actions and, in turn, informs new actions. My design for the research cycles involved three key phases. The following Figure 1 uses nested circles to name the phases and to show how each phase arose from and embodied the previous one.



Figure 1: Nested research phases

The Entry Phase

As part of the entry phase of the research, I met with the teacher to design my initial visits to the classroom and the first iteration of action research. During the entry phase, we arranged meetings to discuss the audio-visual recording, the observation of students during mathematics lessons in their traditional classroom setting and the opening of the classroom space for OST sessions. The entry phase generated five hours of audio and visual recordings of the classroom. I also included teacher and student interviews. The transcripts of these recordings and observations were critical in establishing the extent to which students, given the minimum conditions for emergence, might form, dissolve and/or reform links among themselves, thereby creating a viable network or system. As researcher, I remained within the environment and also took notes on the classroom events. These observations and notes provided important detail and reference points to support my reviews of the video recordings. The resulting transcript was sent to the teacher for review and comments.

It was important not to pre-plan every eventuality for the research phases from a complexity thinking and OST methodology perspective. To avoid undue centralized authority, we returned to Owen's provisos for OST facilitators, "Whatever happens is the only thing that could have, a reminder that real learning and real progress will only take place when we all move beyond our original agendas and convention-bound expectations" (Owen, 1997a, p. 96). Holding space, not directing it, would be critical to the complex system's viability. In this way the facilitator might occasion or anticipate emergence (Stanley, 2009; Davis \& Sumara, 2006) rather than cause it. Davis and Simmt's words also echoed this notion when they wrote, "Pragmatically speaking, decisions around planning 
are more about setting boundaries and conditions for activity than about predetermining outcomes and means - proscription rather than prescription" (2003, p. 147). In the classroom, the notions of self-organization and decentralized control would mean providing significant autonomy to students who, typically, are very accustomed to being told what to do and when to do it. For the classroom teacher this would mean a significant 'letting go' (Davis, Sumara \& Luce-Kapler, 2000; Davis \& Sumara, 2006; McCrone, 2005; Van de Walle, Folk, Karp, \& Ba-Williams, 2011) of her role as the authority for this group of students. Taking a proscriptive approach in the design represented a more open view for this research, as we considered ways in which to set the bounds of acceptable behavior (OST's four principles and one law of mobility) and offer the conditions of complexity thinking (e.g., self-organization decentralized control) to expand the space for the possibilities of emergence.

\section{The Intervention Phase}

The intervention phase began by using the experiences and data from the entry phase as a new starting point for re-considering, with the teacher, the OST methodology. This is consistent with the iterative or recursive process of complexity thinking research, where recursive refers to the act or process of returning or going back in a self-similar way (Oxford Dictionary, n.d.). I chose to represent the cycles as nested circles, as I had done to show the research phases, with each cycle emerging from the other in concentric and expanding circles (Figure 2).

Figure 2: Recursive




I integrated the principle of participatory, cyclical and iterative process of action research with the recursive process of complexity thinking to create a design for my own research. The nested circles represent the recurring and overlapping themes emerging in each conversation circle being "brought forth" (Kieren \& Simmt, 2009) through each iterative cycle rather than lost, as students build new knowledge and explore original ideas and questions. Here, a richer picture of the shared knowledge of the collective is possible, when the recursive cycle goes unbroken. For the action researcher concerned with the collective responsibility of maintaining a viable and complex learning system, this design may generate surprising outcomes.

The intervention phase proceeded by introducing the students and teacher to the OST intervention. For the OST sessions I positioned cameras and recording devices as shown in Figure 3. This documented the conversations and provided data from which to create the visual mapping. I transcribed the data for each session and reviewed them with the teacher before the next iteration began.



Figure 3: Location of recording devices 
This process afforded us a period of reflection. Phelps and Hase remind me that, "Integral to action research is the notion of reflexivity, which might be defined as a mental process in which one thinks about things by going back over them" (2002, p. 516). This period of reflexivity allowed us to question the preceding session(s), attend to logistical or technical issues and challenge assumptions and beliefs about the intervention. For example, during the reflection phase of an early iteration of the action research cycles, the teacher and I met to design a new theme and worked out the required time element, given the restrictions of the school timetable. During the subsequent OST session, this theme, "Issues and opportunities for learning about patterns and patterning in mathematics," stimulated students to offer the following topics for the circle conversations: Patterns and Patterning in Times Tables (PPTT), Word Problems (WP), Patterns in Dividing (PD), and Art and Design in Mathematical Forms (ADMF) around which they self-organized according to their interests.

\section{The Analysis Phase}

The analysis phase provided, with speaking rights and social relationships (Cazden, 2001) in mind, clarity and insight into the discursive features (Sfard, 2007) of the complex learning system, and answered such questions as who participates and how (Hand, 2010; Lemke, 1990). The classroom mapping tool I created enabled me to make such participation and the social relationships visible. Meticulously documenting student movement helped me observe patterns of interaction and identify social networks among students (Figure 4).



Figure 4: Classroom Mapping: Ethan and Donnie 
The purpose of my analysis was to determine how and if ideas moved through the space when math talk was stimulated by the new structure of OST. With students re-locating and sharing thoughts and words with each other they might cross-pollinate the conversations with insights from their original groups or simply join in on a conversation, engaging with the new material without reference to previous conversations. Both examples, in complexity thinking terms, create neighbor interactions. Classroom mapping made visible the students' interactions and connectedness to show the diverse nature of particular groupings or the redundancy of others. Specifically, I used PowerPoint to construct slides tracing student movement through the space, which created a visual, animated representation of this movement. I assigned a different color to each student and, as they moved through the space, I documented each relocation and, ultimately, their trajectory in that color. The color assigned matched the clothing visible on the video recording to facilitate the review of their movements and ensure greater accuracy in the classroom mapping. At first glance, OST can appear chaotic, as students move, often frequently, through the space. My classroom mapping tool helped me see the patterns within what sometimes presented as chaotic activity. The mapping made clearly visible the organized randomness of the students' self-organization.

\section{DATA ANALYSIS}

I began my analysis by studying the video recordings of all OST sessions and undertaking the classroom mapping rather than immediately delving into discourse analysis. I wanted to focus the initial analysis of the data on the physical environment and the students' movement to establish context; for example, knowing which conversations preceded or followed any given conversation often provided insight. Then, analyzing the transcripts, in conjunction with mapping movement, illuminated the sharing and take-up of ideas around the room. Student movement through the space thus became a significant feature of how the students participated in the classroom discourse.

I created multiple iterations of classroom mappings for each OST session to fully analyze student movement. The mapping gave me an alternative way of seeing and understanding the data on the video recordings and enabled the comparison of student movement individually and across groupings.

\section{Mapping the Individual}

In one version of the mapping, for example, I showed all the movements of a single student (Figure 5). 


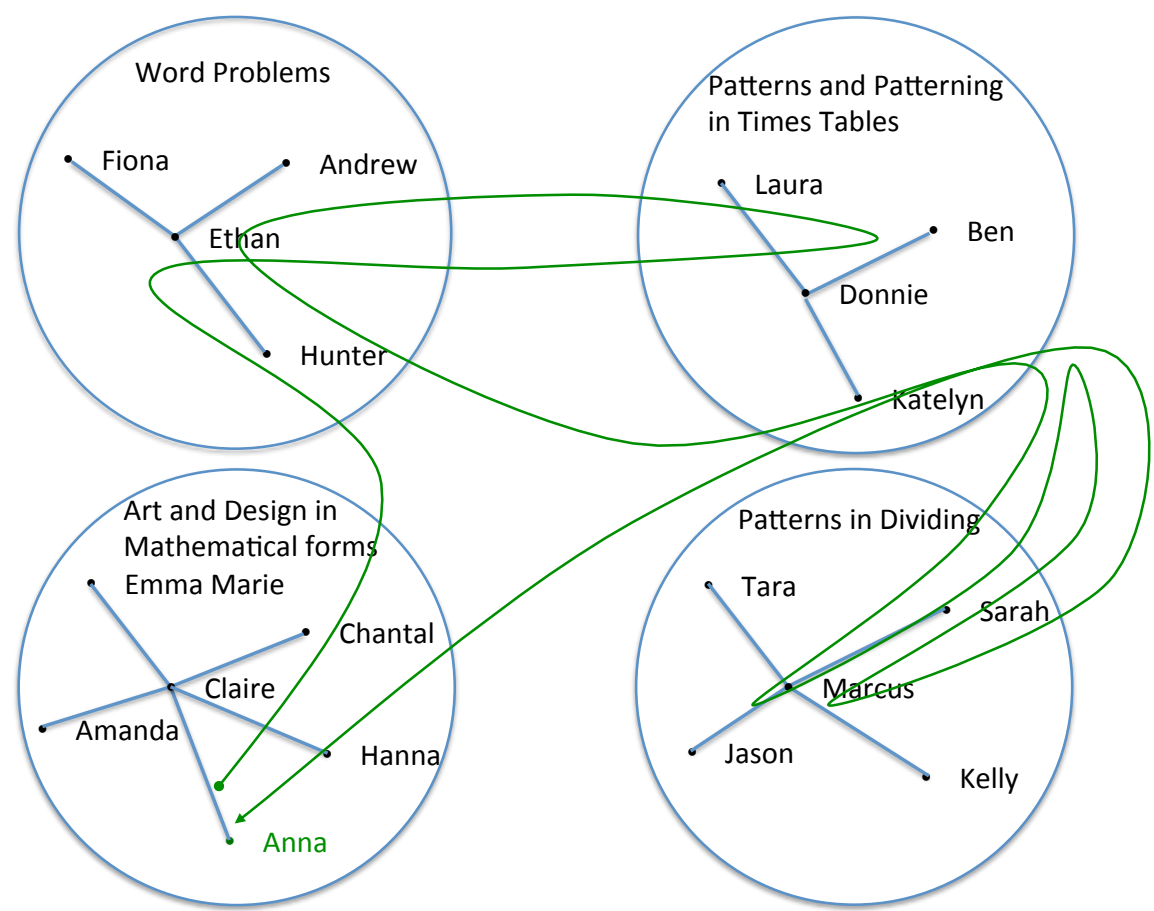

Figure 5: Anna's movement from ADMF

Classroom mapping illustrates Anna's movement, beginning at her home group (ADMF), with multiple visits to each of the other three groups before returning to the ADMF conversation. I recognized a similar pattern with another student (Figure 6): Andrew visited multiple conversations before returning to his original group. The classroom mapping illuminated these patterns and, by confirming their presence in the various conversations, tracking the trajectory of their contributions was made easier.

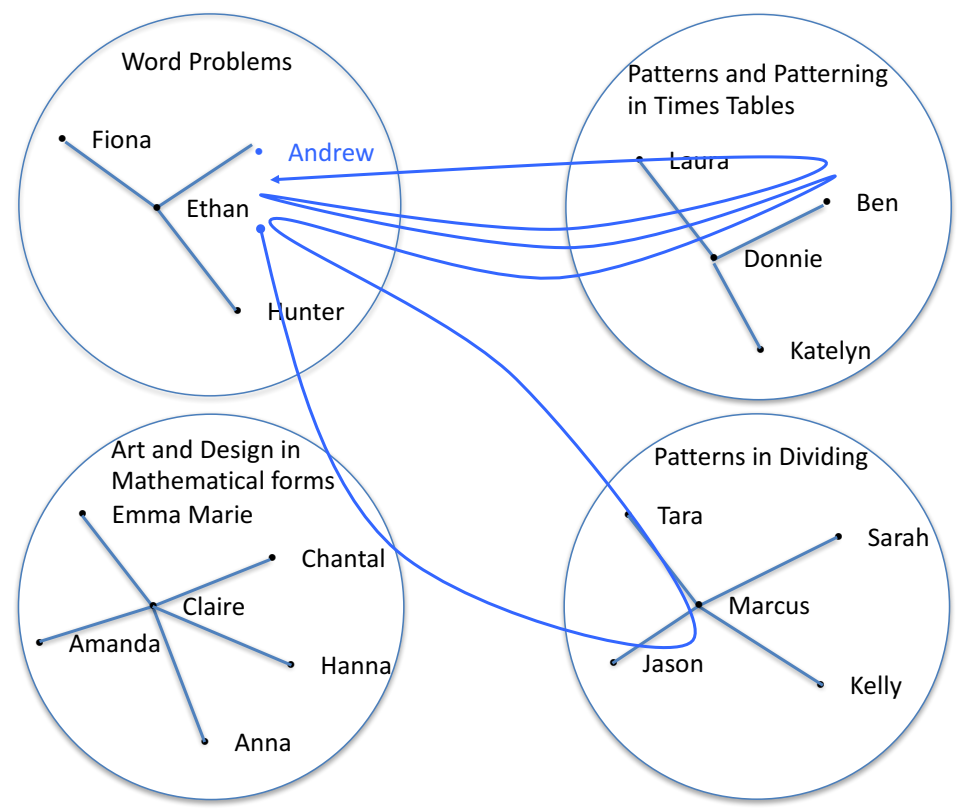

Figure 6: Andrew's Movement from WP 
Other maps helped me see other patterns relating to the cross-pollination of ideas or the function of seemingly peripheral comments. In OST, these patterns of movement are referred to as, in the first case, Bumblebees and, in the second, as Butterflies. Students, presenting as Bumblebees or Butterflies, contributed to the math talk in interesting ways.

\title{
Butterflies
}

Owen describes Butterflies as "rather a different sort.... If you watch a Butterfly over time, you will notice that every so often somebody will stop by. Maybe conversation will occur, maybe not, but if it does it almost inevitably ends up being significant" (1997a, p. 100). In my analysis an exchange is significant or meaningful when it enhances the sequence development by adding relevant information, questioning issues, challenging ideas or offering encouragement. Within this classroom setting, some students acted as Butterflies and dropped by a new group even briefly to inquire, "What are you talking about?" and "What's going on here?" Andrew, from the WP circle for example, visited the other groups and, after listening in on the group, contributed an encouraging comment before continuing on his walk:

\author{
Extract 5.6 \\ 156 Andrew: I think that this group is really cool. \\ 157 Ethan: $\quad$...because Jason's group is talking about wrestling. \\ 158 Fiona: $\quad$ You need patterns to make sense... \\ 159 Andrew: I'm going to go walk around ok? \\ 160 Ethan: $\quad$ Ok.
}

\section{Transcript 5.2}

Arguably, Andrew contributes positively to the group's conversation (line 156) and so may not entirely exhibit the butterfly traits of standing aside or hovering. However, it is clear from Andrew's second comment (line 159) that his intention is to continue on his way. In this way, I interpret Andrew's words as a word of encouragement that could enhance further exchanges among the participants. It is not clear from his words whether he might join a conversation at some point or not; however, classroom mapping (Figure 6) shows that Andrew does visit the PD and the PPTT groups (multiple times to the latter conversation) before returning to the WP group. In this way, butterflies, as unexpected centers of inaction, may help create new possibilities for fruitful conversations and unintentionally open up new avenues of exploration for others.

The potential for classroom mapping to illuminate and track these sometimes fleeting interactions is significant for discourse analysts. Without the mapping this movement might have passed unnoticed.

\section{Bumblebees}

Other students visited new conversations and brought ideas from their previous group with them, often interjecting and connecting one topic to the next. These are the 
Bumblebees in OST (Owen, 1997a). For example, one student from the WP circle, Fiona, joined the PPTT group midway through the session:

\section{Extract 5.7}

48 Fiona:

49 Katelyn:

50 Fiona:

51 Katelyn:

52 Fiona:
What about word problems like what we were doing?

Word problems? ... We've got times tables. They're ...

I think that times tables and patterns mixed together...go... you can put them together in problems.

Times tables are something like patterns...

It also works with dividing.

\section{Transcript 5.2}

This exchange is what Owen refers to as an important contribution of the Bumblebees in OST, "Like their counterparts in nature, they pollinate and cross-pollinate, lending richness and variety to the discussions" (1997a, p. 100). Even in this concise exchange I am struck by its meaning, beginning with Fiona's initial inquiry (line 48). With this question, Fiona makes an offer to share something about what they were talking about in her previous conversation with the new group (Figure 7). She is immediately blocked with a no and a correction from Katelyn (line 49) instead of a more positive, "Yes, and..." to broaden the conversation; yet, proceeds with a proposition (line 50) to build on what the two groups are talking about in general: patterns. Katelyn then accepts Fiona's conjecture (line 51) with acknowledgement of her contribution. Katelyn, perhaps, seeks to continue the topic and build upon it, while Fiona also explores a possible new concept (e.g., dividing, line 52) that expands the conversation even further.



Figure 7: Fiona's Movement from WP 
Another example of the Bumblebee phenomenon follows when two participants, Hunter and Andrew, who have recently joined the ADMF conversation, are asked directly by the convener, Claire, to provide new information for the group:

\section{Extract 5.8}

73 Claire:

74 Hunter:

75 Claire: $\quad$ Yeah, like when do you use patterns?

76 Hunter: What?

77 Claire: $\quad$ In math. When do you use patterns?

78 Hunter: In math?

79 Claire: $\quad$ Andrew when do you use patterns?

80 Andrew: $\quad$ Ahh... everyday really.

81 Claire: $\quad$ No, but most generally where do you use patterns?

82 Andrew: Games.

83 Hunter: Yeah, in games.

84 Andrew: $\quad$ My...I use patterns mostly in my house. I like count ... or something...

85 Hunter: $\quad$ I ... use patterns all the time.

86 Claire: $\quad$ Me too.

87 Andrew: You know what else I do? I count ... all the time and I'll be like, "Where are all the ones?" and then I'll do it with the tens... and do it again with hundreds.

\section{Transcript 5.2}

Claire, by asking direct questions in rapid succession (lines 73, 75, and 77), insists that new members joining her group make contributions. In response and somewhat taken aback, (Me? What? In math?), Hunter becomes silent for a moment. Claire's tone, as evidenced in the audio tapes, betrays her impatience, when she turns to the second newcomer and directs similar questions at Andrew (lines 79 and 81). Andrew is quick to reply and Hunter quickly agrees with the example and then generalizes his statement, by acknowledging that he uses patterns all the time (lines 82-85). Andrew, meanwhile, contributes a second specific example to the group (line 87), an example of a patterning situation that he has observed while counting. Andrew and Hunter, coming from the WP group (Figure 8), had conversed about their favorite video games and debated the size of a popular wrestler's fan base; therefore, it is not surprising as Bumblebees that their examples would be ones focused on counting, and, in particular, finding patterns in counting and games. Hunter contributes his support of Andrew's responses to Claire's questions and subsequently returns to his original WP conversation. 


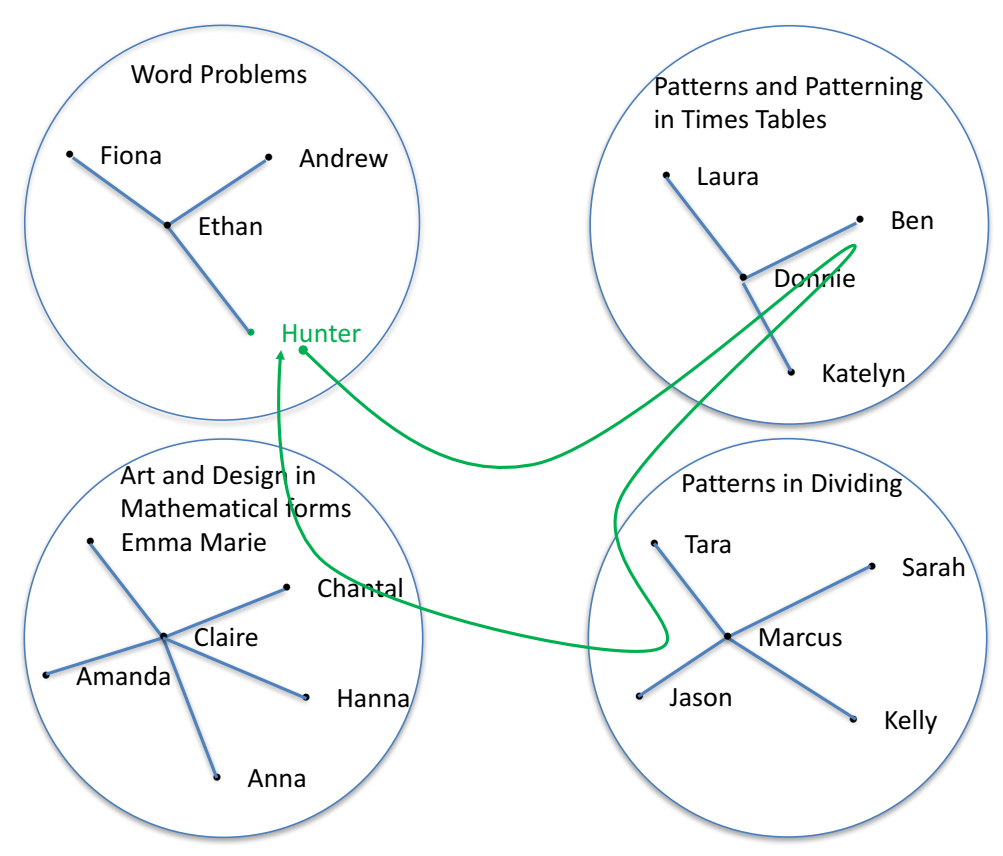

Figure 8: Hunter's Movement from WP

In the above mapping examples, of students' movements, I've inserted excerpts from the transcripts to illustrate how the individual patterns lead to understanding discourse in a context (e.g., the bumblebees bringing an idea from a previous conversation into a new conversation). Without the classroom mapping, it would have been very difficult to understand how the ideas moved and grew. The mapping helped me recognize how Andrew and Hunter's movement enriched the math talk by bringing forward ideas and examples from previous conversations (WP) into a new one (ADMF). From a complexity thinking perspective, the classroom conversation as a whole deepened with the simple contributions and actions of two students that became visible through mapping.

Mapping the Group

Layering multiple students' movements also proved fruitful. For example, for each group I created a map illustrating each student's movements and then combined them onto one slide (Figure 9). Through this mapping, I was able to see clearly that all group members visited other conversations and could easily see the number of interactions with other groups thereby providing a context for further investigation using the audio recordings. 


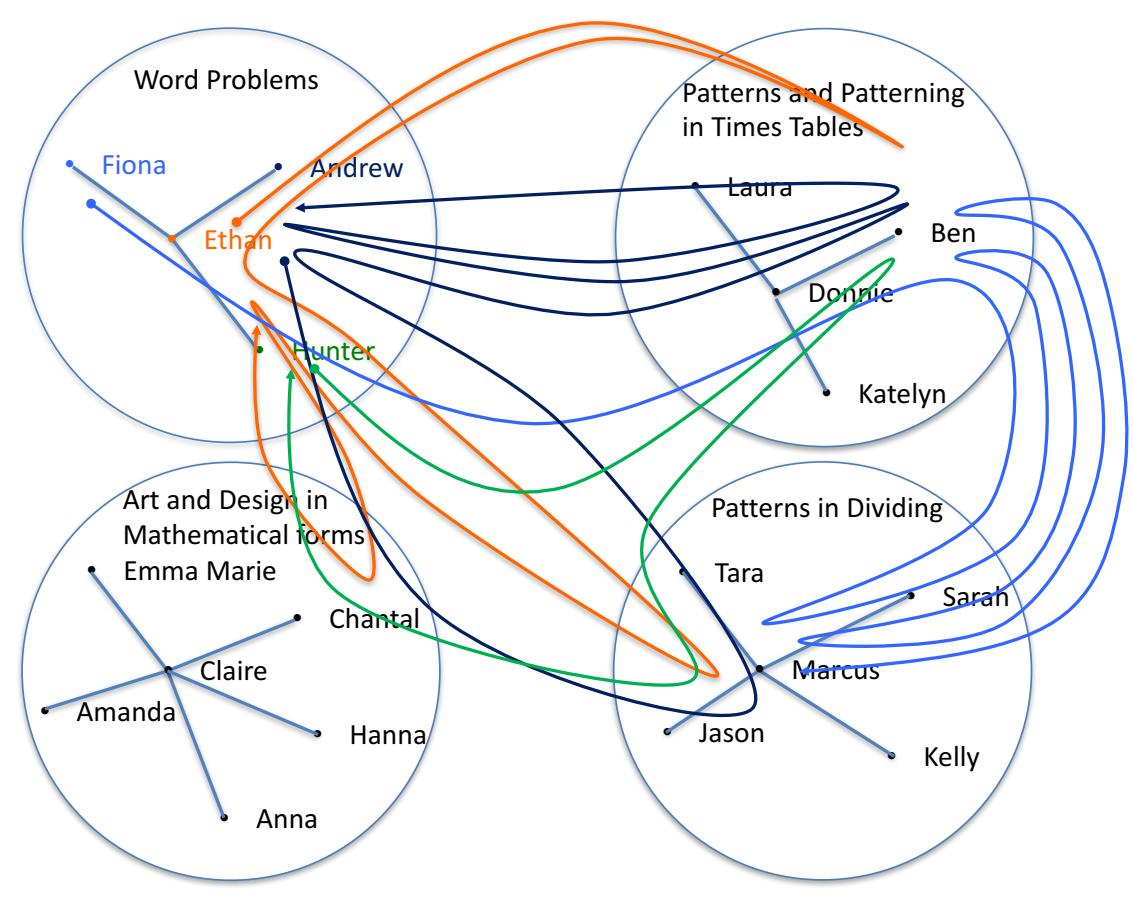

Figure 9: Movement from the WP circle Figure 5.6

Listening to these conversations and members' contributions was also insightful. For example, in the ADMF group, the convener, Claire, used a directive style as convener, adopting the role of teacher and potentially making The Law of Mobility more challenging to follow (Figure 10). The map of this group's movement shows less movement toward other conversations with two students, Chantal and Hanna, leaving their group briefly and returning to it almost immediately. A third student, Anna, as previously noted, visited all the groups repeatedly and interacted in each conversation with the expected social behavior of a Butterfly: her movement back and forth between the PPTT and PD groups, in particular, making connections and building a stronger network among students. Claire's leadership of the ADMF group successfully combined notions of literacy with numeracy and moved the subject matter toward an inter-disciplinary approach with the challenge of creating math poetry. Through their use of math words and narrative, Claire's group participated in close interaction to build and communicate knowledge together. Their collaborative exchanges were characterized by a willingness to negotiate a task through clarifying, accepting, and summarizing each other's contributions even under the assertive style of Claire's hosting. She fostered a greater appreciation of doing and talking about mathematics by focusing specifically on making connection through mathematics language and enriching the opportunities for building knowledge among her peers. 


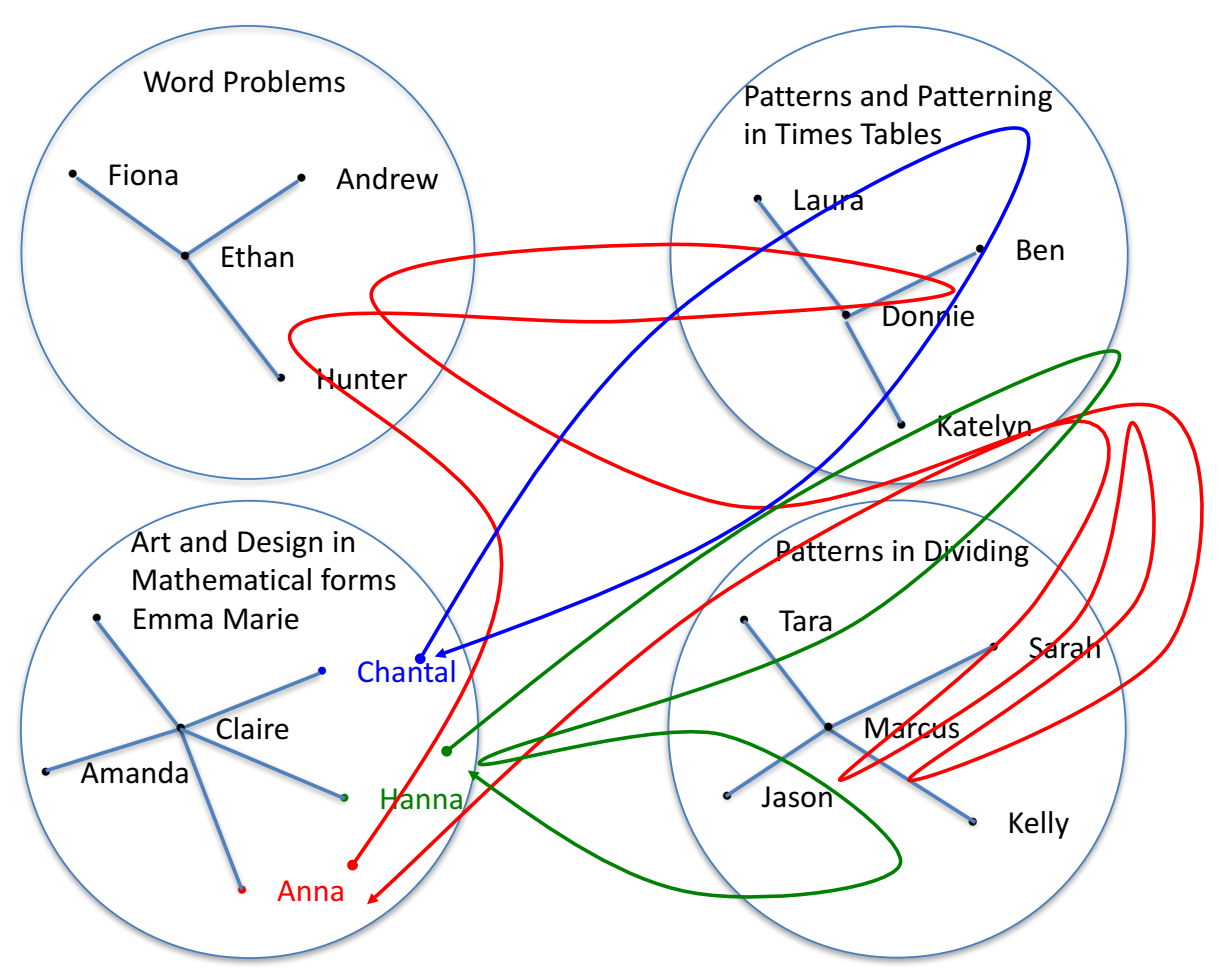

Figure 10: Movement of ADMF Group

Claire's challenge also brought about new ways of talking about and doing math for the participants as they huddled around her. Students in the ADMF group, for a time, responded to Claire's directive nature and willingly tried something new. A consolidation of ideas, for example, occurred as they successfully completed the poem.

\section{Mapping the Classroom}

In addition, I combined all group maps to create a single view of the OST session. When examined as a whole, the classroom mapping made visible the entire student body of movement through the space. This mapping makes visible the overall student energy. When all student movement is represented, a complex network of connections in the classroom emerges. Not only are the students' movements made visible but the energy generated from the movement is also represented, sometimes to quite dramatic effect. For example, Figure 11 illustrates the students' movements and shows engagement hubs where student interaction is most numerous.

When examining the classroom map of the entire class, clusters of energy or loci of students' interests around specific topics became apparent. For example, the PPTT grouping draws significant attention, as participants contribute to or listen in on key topics suggested by the general theme of the session. In this circle, Donnie, the convener, suggests everyone make connections with patterns in their lives, outside the mathematics classroom, thereby engaging his participants directly. Meanwhile, the original cluster of four students, comprising the WP circle, draws significant energy from visiting students who contribute to the creation of original problems for the group to solve. Those students leave the WP circle; yet, subsequently, re-visit and remain committed to the word problems 
for the duration of the session. Concurrently and independent of each other, two students visit the PD and PPTT circles, repeatedly, fulfilling Donnie's request for connections in patterning and contributing to the on-going conversation of the former around procedural accuracy in dividing. As evidenced in the classroom mapping, even the students who appeared to dis-engage from their original groupings were still 'in the ballgame' and, in each case, continued to contribute to the sessions.



Figure 11: All student movement

With the classroom mapping I was able to gauge more clearly the topics attracting the most energy and so focus attention on the corresponding audio recordings. The mapping showed which topics became the focus centers, as certain groups appeared to draw more interest and therefore generate more movement than others. The WP and PPTT conversations showed the greatest movements in and out, while those students at the ADMF and PD conversations largely remained in their original conversations. The mapping easily enables the researcher to see, at a glance, where great or little movement has occurred. Movement also can shine a spotlight on a different energy - the energy of rooted engagement and concentration, where students chose to remain in one conversation for the duration of OST.

The classroom map brought this into focus with the students in the PD group choosing largely to stay with the topic that they had first chosen. A brief extract from their 
conversation illustrates the group's focused energy for opening up the contexts for problem solving strategically (line 105):

\author{
Extract 7.7 \\ 105 Chantal: Can we use different strategies? \\ 106Anna: What's your other strategy? \\ 107 Donnie: Yeah, let's try to make up one. \\ 108 Chantal: We can all think of one. \\ 109 Donnie: I think if everybody made up a strategy and then we did \\ them. \\ 110 Kelly: What? \\ 111 Donnie: And then each other does their own strategy. \\ 112 Chantal: Tell Ms. Stuart. \\ 113 Marcus: I know one. I love your group; it's fun. \\ 114 Kelly: Next time, I'm going to make a group. \\ 115 Chantal: I wish I was a group leader. \\ $116 \ldots$ [inaudible] \\ 117 Kelly: $\quad$ So do I.
}

\title{
Transcript 7.2
}

Anna, Donnie and Chantal all encourage the group to explore and invent other strategies to push the group's thinking further. The self-directed nature of Donnie's proposal speaks to the power of setting minimal conditions to generate participant accountability for learning thereby rendering the intervention of an authority unnecessary. Even when Chantal requests that the group inform Ms. Stuart about their new change in direction (line 112), no one picks up on her request. The group has established its autonomy and accountability. This group has created momentum and this energy attracts Marcus, a Bumblebee, who experiences this creativity as 'fun'. Coming together to explore a topic builds energy and uplifts the group creating a sense of fun and engagement.

\section{REFLECTION}

An initial consequence of OST was the relocation of students in the classroom space and their increased movement throughout it. What became immediately noticeable to me through classroom mapping was the adoption by students of the Law of Mobility and their eagerness to become either a Butterfly or a Bumblebee. Student comments indicated a sense of pride (e.g., "I'm a Butterfly") and a justification for joining a group (e.g., "Oh yeah, I'm a Butterfly"). Some students were drawn to the role more than others, often adopting the same role in subsequent OST sessions. It is interesting to note that these are the same students who might regularly disrupt the flow of the teacher's lesson with interruptions and requests to sharpen pencils or go to the bathroom (Teacher Interview, Transcript 3.1). Many students in the video recordings of their traditional classroom environment demonstrated non-compliance in these ways; yet, in the learning environment of OST, there is no non-compliance or 'opting out'. Every choice is legitimized thereby maintaining an invitational space for further engagement. These roles allow participants to remain in 
the conversation, creating an inclusive space, thereby supporting the math discourse. In addition, as OST values the roles of observer and cross-pollinator of ideas, many students willingly share ideas gathered from others or share lessons learned. On the surface, these students may appear to have opted out of the classroom activities; however, the mapping and audio data show that this is not the case. Classroom mapping ensured that no data was lost in this space, as all movement and choices were documented.

Classroom mapping provides a picture of the complex learning system unique to a particular classroom and assists in illustrating students' engagement, their disengagement at times, and their often surprising re-engagement in different locations. In my experience as a classroom teacher, the organization of seating plans or teacher-assigned groups is a dominant practice that carried over into early discussions about the introductory OST session. Yet, changing the classroom structure in a profound way, from removing the desks, tables and assigned seats to having students set the topics for the conversations, provided an opportunity for all students to participate and practice math talk more fully. The visual image of student engagement together with discursive analysis of students' accountability offers teachers and researchers a richer appreciation of the complexity emerging in this learning system.

For the classroom teacher, the action research cycles provided critical reflective opportunities for instructional practice and decisions. As a new methodology, OST opened up classroom discourse significantly with more meaningful exchanges documented through audio recordings and increased student-to-student interactions and engagement observed through classroom mapping. Students demonstrated more sustained conversation and accountability for learning in conversation circles as time constraints were reduced and space opened for thinking and talking about topics of interest to the students. For the researcher, the mapping tool provided an opportunity to see the movement and interaction of all participants of the complex system as well as follow the development of ideas around the room as evidenced in the contributions of significant butterflies and bumblebees. In collaboration, the researcher and the teacher enjoyed a fuller picture of the classroom discourse that, in their recursive visual and auditory analysis, helped them see and hear students as they shared, built and ultimately explored knowledge together. The subsequent analysis phase of this research will examine these discursive practices more fully through the development of a complexity thinking analytic lens for classroom discourse.

\section{CONCLUDING THOUGHTS}

Complexity thinking provided an apt methodology within which to locate the action research design. This focused the design on the self-organizing and collective possibilities of the complex system. It also illuminated, through classroom mapping, aspects of the emergent properties of the classroom wherein student exchanges and interactions were identified as students took up the discourse of mathematics and engaged in mathematical activity. As Hase stated, "Action research provides the opportunity to look at phenomenon while it is evolving... and a chance to look at the potentially myriad variables that might be 
coming into play as they occur" (2000, p. 4). A complexity thinking view embraces and acknowledges similar notions, like the multiplicity of variables and unpredictability of an evolving system, and asks action researchers to consider them at each iteration of the design cycle. Laidlaw supported this work with her description of subtle influences or "how chaotic systems amplify very small differences within themselves, often producing profound results" (2005, p. 40). This action research located the research within the mathematics classroom to generate data from subtle influences brought about through the OST intervention and to make visible an emerging complex learning system in action.

In terms of complexity thinking, the OST intervention also relocated the learners from a traditional classroom to a self-organizing, open space classroom. The temporary changes to the classroom, created by meeting the necessary minimum conditions of complexity, generated small networks among the students, increased students' responsibility to selfmotivate, and fostered the flow of information and knowledge through the system. Classroom mapping made the many interactions of a complex learning system visible. For example, the mapping identified diverse groupings of students, redundant in their passion for a specific topic, and followed their movements through an open space, as they found authentic ways to contribute within a network of their peers. The mapping represented visually the provision of the OST methodology for organized randomness to afford students self-organizing possibilities and accountability to engage in their own learning. Students showed their accountability by joining circle conversations and, if they chose the Butterfly role, continued to remain part of the process as a curious on-looker might observe an intriguing event, even from the periphery. A model of decentralized control arose as the teacher opened and held space for her students to move and talk in contrast to more teacher-centered pedagogies concerned with classroom management and 'appropriate' classroom behavior. Opportunities for neighbor interactions arose through the students' talk as ideas were shared and exchanged. Significantly, to illuminate classroom discourse, the ideas moving around the room became visible through classroom mapping and were subsequently verified through transcript analysis. The Law of Mobility ensured a more robust system, as Bumblebees moved around the space cross-pollinating ideas and interjecting new ideas as they joined various conversations. In these ways, teachers may find OST useful in promoting discourse, especially in mathematics where an increased emphasis on communicating understanding ensures that students become true participants in the mathematics discourse, and classroom mapping beneficial in visualizing the complex learning system emerging through meaningful exchanges.

I chose recursive action research cycles for the OST intervention to illustrate how each iteration of analysis unfolded from the next, allowing me to see at once, the whole research cycle from entry to intervention to analysis, along with its recursive parts from initial observations to the OST sessions and the mapping process. Critical to the design was consideration at all levels of analysis of the minimum conditions for emergence. Classroom mapping provided a concrete tool from which to view the complexity of classroom dynamics in detail. The mapping, along with transcript analysis, showed evidence of idea sharing and movement throughout the space that resulted in a rich network of students engaged in meaningful conversation and accountable for their learning in a variety of ways. 
Also critical was the consideration of all system participants and accounting for all forms of engagement with classroom discourse. The OST intervention allowed for these possibilities, as students could opt out of the intervention; yet, still remain part of the learning system, maintaining freedom of choice and contributing in appropriate ways. In OST these are the Bumblebees and Butterflies in the system. In complexity thinking terms, the nature of this intervention provided opportunity and space for the emergence of a student-centered, self-organizing system made more visible through the creation of a tool for mapping complexity.

\section{REFERENCES}

Brooks, L. A., \& Dixon, J. K. (2013). Changing the rules to increase discourse. Teaching Children Mathematics, 20(2), 84-89.

Capra, F. (1996). The web of life: A new scientific understanding of living systems. New York, NY: Anchor Books.

Carr, W., \& Kemmis, S. (1986). Becoming critical: Education, knowledge, and action research. London, UK: The Falmer Press.

Cazden, C. (2001). Classroom discourse: The language of teaching and learning (2nd ed.). Portsmouth, NH: Heinemann.

Chapin, S. H., O'Connor, C., \& Canavan-Anderson, N. (2003). Classroom discussions: Using math talk to help students learn, Grades 1-6. Sausalito, CA: Math Solutions Publications.

Chapman, 0. (2009). Learner-focused discourse in learning mathematics: A teacher's perspective. In S. L. Swars, D. W. Stinson, \& S. Lemons-Smith (Eds.), Proceedings of the 31st annual meeting of the North American chapter of the international group for the psychology of mathematics education (pp. 328-336). Atlanta, GA: Georgia State University.

Cobb, P., Wood, T., \& Yackel, E. (1993). Discourse, mathematical thinking, and classroom practice. In E. A. Forman, N. Minick, \& C. A. Stone (Eds.), Contexts for learning: Sociocultural dynamics in children's development, (pp. 91-119). New York, NY: Oxford University Press.

Corrigan, C. (2002a). Open space technology and the legacy of education. Retrieved from www.chriscorrigan.com

Corrigan, C. (2002b). Planning an open space technology meeting. Retrieved from www.chriscorrigan.com 
Daniel, M. W. (1994). An ethnographic study of an open space technology meeting: Selforganization at work (Doctoral dissertation). Retrieved from ProQuest Dissertations \& Theses Full Text. (Order No. 9514512)

Davis, B., \& Simmt, E. (2003). Understanding learning systems: Mathematics education and complexity science. Journal for Research in Mathematics Education, 34(2), 137-167.

Davis, B., \& Sumara, D. (2005). Challenging images of knowing: Complexity science and educational research. International Journal of Qualitative Studies in Education, 18(3), 305-321.

Davis, B., \& Sumara, D. (2006). Complexity and education: Inquiries into learning, teaching, and research. Mahwah, NJ: Lawrence Erlbaum Associates.

Davis, B., Sumara, D., \& Luce-Kapler, R. (2000). Engaging minds: Learning and teaching in a complex world. London: Lawrence Erlbaum Associates.

Davis, B., Sumara, D., \& Luce-Kapler, R. (2008). Engaging minds: Changing teaching in complex times, $2^{\text {nd }}$ edition. New York, NY: Routledge.

Dekker, R., \& Elshout-Mohr, M. (2004). Teacher interventions aimed at mathematical level raising during collaborative learning. Educational Studies in Mathematics, $56,39-65$.

Dekker, R., Elshout-Mohr, M., \& Wood, T. (2006). How children regulate their own collaborative learning. Educational Studies in Mathematics, 62, 57-79. doi: $10.1007 / \mathrm{s} 10649-006-1688-4$

Doll, W. E. Jr. (1989). Complexity in the classroom. Educational Leadership, 47(1), 65-70.

Forman, E., \& Ansell, E. (2001). The multiple voices of a mathematics classroom community. Educational Studies in Mathematics, 46(1), 115-142.

Fuchs, L., Fuchs, D., Powell, S., Seethaler, P., Cirino, P., \& Fletcher, J. (2008). Intensive intervention for students with mathematics disabilities: Seven principals of effective practice. Learning Disability Quarterly, 31(2), 79-92.

Garrett, T. (2008). Student-centered and teacher-centered classroom management: A case study of three elementary teachers. Journal of Classroom Interaction, 43(1), 34-47.

Gee, J. P. (2011). How to do discourse analysis: A toolkit. New York, NY: Routledge.

Gersten, R., Jordan, N., \& Flojo, J. (2005). Early identification and interventions for students with mathematics difficulties. Journal of Learning Disabilities, 38(4), 293304. 
Gleick, J. (1987). Chaos: Making a new science. New York, N.Y: Viking.

Greene, M. (1986). In search of a critical pedagogy. Harvard Educational Review, 56(4), 427-442. doi: http://dx.doi.org/10.17763/haer.56.4.010756lh36u16213

Greene, M. (1993). Teacher as stranger. Boston, MA: Wadsworth Publishing.

Hand, V. M. (2010). The co-construction of opposition in a low-track mathematics classroom. American Educational Research Journal, 47(1), 97-132.

Hase, S. (2000). Mixing methodologies in research. Paper presented at the $9^{\text {th }}$ Vocational education and training research (NCVER) conference, Coffs Harbour, NSW. Retrieved from http://www.ncver.edu.au/research/papers/trconf9.htm

Heft, L. (2005). The open space technology idea book. Retrieved from www.openingspace.net

Henning, J. E. (2005). Leading discussions opening up the conversation. College Teaching, 53(3), 90-94.

Herman, M., \& Corrigan, C. (Eds.). (2002). Open space technology: A user's non-guide. Retrieved from www.chriscorrigan.com

Herr, K., \& Anderson, G. L. (2005). The action research dissertation: A guide for students and faculty. Thousand Oaks, CA: SAGE.

Janzen, H. (2005). Intervention strategies for mathematics teachers. Retrieved from http://www.glencoe.com/sec/teachingtoday/subject/intervention_strategies

Johnson, S. (2001). Emergence: The connected lives of ants, brains, cities, and software. New York, NY: Scribner.

Kamii, C. (2000). Young children reinvent arithmetic: Implications of Piaget's theory, $2^{\text {nd }}$ edition. New York, NY: Teacher's College Press.

Kemmis, S., \& McTaggart, R. (1988). The action research planner. Geelong: Deakin University Press.

Kieren, T., \& Simmt, E. (2009). Brought forth in bringing forth: The interactions and products of a collective learning system. Complicity: An International Journal of Complexity and Education, 6(2), 20-28.

Kincheloe, J., \& Berry, K. (2004). Rigour and complexity in educational research: Conceptualizing the bricolage. Maidenhead, UK: Open University Press.

Kotsopoulos, D. (2007). Mathematics discourse: It's like hearing a foreign language. Mathematics Teacher, 101(4), 301-305. 
Laidlaw, L. (2005). New maps: Complexity, learning and writing. In Reinventing curriculum: A complex perspective on literacy and writing, (pp. 25-58). Mahwah, NJ: Lawrence Erlbaum Associates Publishing.

Lampert, M. (1990). When the problem is not the question and the solution is not the answer: Mathematical knowing and teaching. American Educational Research Journal, 27, 29-63.

Lemke, J. L. (1990). Talking science: Language, learning, and values. Norwood, NJ: Ablex Publishing Corporation.

Manouchehri, A., \& St. John, D. (2006). From classroom discussions to group discourse. Mathematics Teacher, 99, 544-551.

McCrone, S. S. (2005). The development of mathematical discussion: An investigation in a fifth-grade classroom. Mathematical thinking and learning, 7(2), 111-133.

McNiff, J., \& Whitehead, J. (2010). You and your action research project. Oxon, UK: Routledge.

Mong, M., \& Mong, K. (2010). Efficacy of two mathematics interventions for enhancing fluency with elementary students. Journal of Behavioral Education, 19(3), 273-288.

Moschkovich, J. (2007). Examining mathematical discourse practices. For the Learning of Mathematics, 27(1), 24-30.

National Council of Teachers of Mathematics (NCTM). (2014). Principles to action: Ensuring mathematical success for all. Reston, VA: Author.

Nichols, S., \& Cormack, P. (2016) Impactful Practitioner Inquiry: The ripple effect on classrooms, schools and teacher professionalism. New York: Teachers College Press.

O'Connor, D. (2005). Participatory processes: Creating a 'marketplace of ideas' with open space technology. The Innovation Journal: The Public Sector Innovation Journal, 10(1), 1-14.

Owen, H. (1997a). Open space technology: A user's guide, $2^{\text {nd }}$ edition. San Francisco, CA: Berrett-Koehler Publishers, Inc.

Owen, H. (1997b). Expanding our now: The story of open space technology. San Francisco, CA: Berrett-Koehler Publishers, Inc.

Owen, H. (2000). The power of spirit: How organizations transform. San Francisco, CA: Berrett-Koehler Publishers, Inc. 
Phelps, R., \& Hase, S. (2002). Complexity and action research: Exploring the theoretical and methodological connections. Educational Action Research, 10(3), 507-523.

Pimm, D. (1987). Speaking mathematically: Communication in mathematics classrooms. London, UK: Routledge.

Recursive. (n.d.). In The Oxford Dictionary. Retrieved October 10, 2014 from http://www.oxforddictionaries.com/definition/english/recursive

Sfard, A. (2007). When the rules of discourse change, but nobody tells you: Making sense of mathematics learning from a commognitive standpoint. The Journal of the Learning Sciences, 16(4), 567-615.

Sherin, M. G. (2002). A balancing act: Developing a discourse community in a mathematics classroom. Journal of Mathematics Teacher Education, 5, 205-233.

Stanley, D. (2009). Complex responsive processes: An alternative interpretation of knowledge, knowing, and understanding. Complicity: An International Journal of Complexity and Education, 6(2), 29-39.

Sumara, D. J., \& Carson, T. R. (1997). Reconceptualizing action research as a living practice. In D. Sumara \& T. Carson (Eds.), Action research as a living practice, Vol 66, (pp. xiiixxxii). New York, NY: Peter Lang.

Towers, J., \& Davis, B. (2002). Structuring occasions. Educational Studies in Mathematics, $49,313-340$.

Truxaw, M. P., \& DeFranco, T. (2008). Mapping mathematics classroom discourse and its implications for models of teaching. Journal for Research in Mathematics Education, 39(5), 489-525.

Van de Walle, J. A., Folk, S., Karp, K. S., \& Bay-Williams, J. M. (2011). Elementary and middle school mathematics: Teaching developmentally, $3^{\text {rd }}$ Canadian edition. Toronto, $\mathrm{ON}$ : Pearson Canada.

Wachira, P., Pourdavood, R. G., \& Skitzki, R. (2013). Mathematics teachers' role in promoting classroom discourse. International Journal for Mathematics Teaching and Learning, January. $\quad$ Retrieved from http://www.cimt.plymouth.ac.uk/journal/wachira.pdf

Waldrop, M. M. (1992). Complexity: The emerging science on the edge of order and chaos. New York, NY: Simon \& Schuster. 


\section{BIOGRAPHICAL NOTE:}

Dr. Evan Throop Robinson is an Assistant Professor at St. Francis Xavier University. He teaches elementary and middle school mathematics curriculum and instruction and assessment courses in the Bachelor of Education, Mathematics Certificate and Master of Education programs. His current research interests focus on communication and critical discourse in the mathematics classroom. 